\title{
The prenatal exclusion test for Huntington's disease: experience in the west of Scotland, 1986-1993
}

\author{
J L Tolmie, H R Davidson, H M May, K McIntosh, J S Paterson, B Smith
}

The Duncan Guthrie Institute of Medical Genetics and Queen Mother's Hospital, Yorkhill Hospitals NHS Trust, Yorkhill, Glasgow G38SJ, UK J L Tolmie

H R Davidson

H M May*

K McIntosh

J S Paterson

B Smith

* Dr Heather May died in 1992.

Correspondence to: Dr Tolmie.

Received 24 July 1994 Revised version accepted for publication 23 September publica

Huntington's disease prenatal exclusions

\begin{tabular}{|c|c|c|c|c|c|c|c|}
\hline \multirow[b]{2}{*}{ Family } & \multicolumn{2}{|c|}{ Age of partners } & \multirow[b]{2}{*}{ Social class* } & \multirow[b]{2}{*}{ Parity } & \multirow[b]{2}{*}{ Date } & \multirow[b]{2}{*}{ Result } & \multirow[b]{2}{*}{ Outcome } \\
\hline & $F$ & $M$ & & & & & \\
\hline 1 & 32 & 28 & II & $1+0$ & May 88 & High risk & STOP \\
\hline 2 & 30 & 30 & I & $0+0$ & Nov 89 & Low risk & ND \\
\hline 3 & 25 & 28 & IV & $0+0$ & Jan 90 & High risk & ND \\
\hline 4 & 27 & 30 & II & $0+0$ & May 90 & High risk & STOP \\
\hline 5 & 34 & 34 & V & $1+0$ & May 91 & Low risk & ND \\
\hline 4 & 28 & 31 & II & $0+1$ & July 91 & High risk & ND \\
\hline 6 & 23 & 25 & V & $0+0$ & Nov 91 & High risk & STOP \\
\hline 7 & 30 & 33 & II & $0+0$ & Feb 92 & Low risk & ND \\
\hline 8 & 30 & 32 & III & $1+0$ & Feb 92 & Low riskf & ND \\
\hline 9 & 37 & 40 & I & $0+0$ & Apr 92 & High risk & STOP \\
\hline 10 & 26 & 29 & III & $0+0$ & Sept 92 & High risk & STOP \\
\hline 5 & 35 & 35 & V & $2+0$ & Oct 92 & High risk & ND \\
\hline 10 & 27 & 30 & III & $0+1$ & Nov 93 & High riskf & STOP \\
\hline
\end{tabular}

$S T O P=$ suction termination of pregnancy; $N D=$ normal delivery. Under the column headed 'Parity' $1+0=1$ liveborn infant and no miscarriages.

* Consultands' social class assignation conforms to the UK Registrar General's five point, occupational based scale.

t The HD mutation was subsequently not detected in the supposedly affected mother of this consultand.

$\ddagger$ This pregnancy is included because an exclusion test was initially planned although it was superseded by a diagnostic test (see text for details).

( $(\mathcal{H}$ Med Genet 1995;32:97-101)

In 1985 Harper and Sarfarazi ${ }^{1}$ proposed prenatal exclusion testing as a method whereby a parent who is at $50 \%$ risk of carrying the gene for Huntington's disease (HD) can elect to have children who are at low risk of being gene carriers by excluding in the fetus the parental allele which is at risk of being linked to the HD gene mutation. In proposing the exclusion test, which uses anonymous, polymorphic markers closely linked to the Huntington's disease gene,

\begin{abstract}
Abstract test for Huntington's disease (HD) has been given to an unselected series of couples who attended the genetic counselling clinic from 1986 onwards. Ten couples underwent 13 prenatal tests during this period with expressed intention of stopping a pregnancy if the result indicated a high risk (almost $50 \%$ ) that the fetus carried the HD gene. Nine fetuses at nearly $50 \%$ risk of carrying the $\mathrm{HD}$ gene were identified but only six such pregnancies were terminated. In each of three high risk pregnancies which continued, the mother made a "final hour" decision not to undergo the scheduled, first trimester termination. In our experience, late reversal of a previous decision to undergo first trimester pregnancy termination for a genetic indication is uniquely frequent among couples who have undergone the prenatal exclusion test for HD.
\end{abstract}

Harper and Sarfarazi ${ }^{1}$ pointed out that it has two main advantages: firstly, since previous determination of the genetic linkage phase between the marker and disease gene in the parent at risk of transmitting the $\mathrm{HD}$ gene to the fetus is not required, the test is available to most families including those where the pedigree structure is unsuitable for conventional presymptomatic testing; secondly, a high risk test result for the fetus does not alter the risk status of the parent. However, implicit in the exclusion test is the assumption that the pregnancy will be terminated if the result indicates the fetus has $50 \%$ risk of carrying the HD gene. If the high risk pregnancy is not terminated then a unique situation may arise, for if the parent develops the condition then the child will most likely (around $96 \%$ probability) become affected also. ${ }^{2}$

Since 1986 , adults at $50 \%$ risk of developing HD who attended the west of Scotland genetic clinic have, as a matter of routine, been informed about the options of presymptomatic predictive testing and prenatal exclusion testing in HD. In this paper we describe our experience of carrying out the prenatal exclusion test in 10 couples who have undergone a total of 13 tests.

\section{The families}

Nine of the 10 couples who subsequently underwent exclusion testing were married and one couple married between their first and second tests. All couples were specifically counselled about the exclusion test at least once in the preconception period by the same geneticist and on a second occasion by the same or another geneticist. Four consultands had the exclusion test explained on three occasions before undergoing chorionic villus sampling (CVS). In addition to receiving oral explanations, consultands were give a leaflet prepared by the United Kingdom Association to Combat Huntington's Disease, which gives details on the working of both presymptomatic and prenatal exclusion tests.

Details of the families and exclusion test outcomes are given in the table. It is notable that in nine out of 10 families, the mother was at $50 \%$ risk of being an $\mathrm{HD}$ gene carrier. As expected, the consultands were either primiparous or of low parity and the mean maternal age of 29 years was increased in keeping with an often stated preference to defer having children until it could be shown that consultands had a low chance of transmitting the 
HD gene. The consultands' social class distribution was broad and indicative of their varied backgrounds. Eight families had more than one relative with a clinical diagnosis of HD but neuropathological confirmation of the diagnosis was available in only one family. Recently, we have shown that in these eight families at least one affected person has the HD triplet expansion mutation. In two families only one person was diagnosed affected by HD and only one of these patients has had the clinical diagnosis confirmed by mutation analysis. In a second sporadic case (family 8) there was no evidence of the HD triplet expansion mutation. However, in that person HD was considered the most likely clinical diagnosis by three experienced clinicians (a neurologist, a psychiatrist, and a geneticist). In eight families pre-exclusion test DNA work up was completed before pregnancy was diagnosed. In the two remaining families DNA work up was started after pregnancy was diagnosed and informative results were obtained before CVS was performed. All CVS procedures were carried out at 10 weeks gestational age in a single prenatal diagnosis unit.

\section{DNA analysis}

One laboratory carried out all DNA analyses and methods have been reported in a previous paper. ${ }^{4}$ Initially, markers defined by the D4S 10 locus were used and subsequently markers from the D4S95 and D4S43 loci were used in combination with various restriction enzymes. The likelihood of the fetus inheriting the gene for HD was calculated with the MLINK programme from the LINKAGE package. ${ }^{5}$

Supplementary details about family circumstances in which each exclusion test was performed are given below. Note that we have not presented details of couples who have indicated they wish to undergo testing but have not yet done so, nor is there information on couples who initially indicated an interest but subsequently withdrew from exclusion testing.

\section{Case histories}

FAMILY 1

In this family, the first in the series, the consultand first attended the genetic clinic in 1982 after her grandmother was diagnosed as having HD. The consultand married and had her first child at the age of 30 years. She was given information about exclusion testing in 1987 at which time the family structure precluded offering a presymptomatic test. An exclusion test was performed in her second pregnancy and following the high risk result and termination of pregnancy, the consultand requested and underwent sterilisation.

\section{FAMILY 2}

This woman deferred having children because of her family history of $\mathrm{HD}$ and opted for an exclusion test only because she was not informative for a presymptomatic test. The exclusion test yielded a good result but subsequently the consultand underwent a predictive test using newer, closely linked markers. Another good result was obtained (96\% reassurance that she does not carry the HD gene), so her second pregnancy proceeded to term without any tests being performed. The consultand then requested that her predictive test result be confirmed by mutation analysis. However, shortly before her result was due to be reported she ordered that it should not be divulged.

\section{FAMILY 3}

This woman was counselled on three occasions about the exclusion test before she underwent CVS. A high risk result was obtained and pregnancy termination was arranged, but after being admitted to hospital and giving signed consent for operation, she changed her mind and discharged herself from hospital.

\section{FAMILY 4}

This woman had counselling about exclusion testing on three occasions, twice before her marriage and once accompanied by her husband. Her first pregnancy was not planned and the consultand requested the exclusion test. The result indicated a high risk (48\%) that the fetus carried the HD gene and she underwent pregnancy termination. Her second pregnancy was planned and she again requested the exclusion test but this time she declined the offer of further formal genetic counselling preferring to proceed straight to chorionic villus sampling at 10 weeks' gestation. Unfortunately, a second high risk result was obtained and pregnancy termination was arranged. However, on the morning of her admission to hospital she decided she could not go through with the procedure and the pregnancy continued to term.

\section{FAMILY 5}

This woman, who had a healthy child by a previous partner, was also seen on three occasions before undergoing an exclusion test in her second pregnancy. A good result was obtained and the pregnancy continued. Early in her second pregnancy she reported to the prenatal diagnosis unit at 5 weeks' gestation and was given further detailed genetic counselling about the exclusion test. After undergoing CVS, a high risk result was obtained and pregnancy termination was arranged. The consultand was admitted to hospital for suction evacuation of the uterus but after settling in the gynaecology ward she decided to leave and, without informing ward staff, she fled through an emergency exit.

\section{FAMILY 6}

This woman was also seen on three separate occasions before having an exclusion test in her first pregnancy. She underwent CVS and a high risk result was obtained. However, on discussing this test result, it was clear that the consultand was confused about its significance 
and her previous apparent understanding of the principle of the exclusion test was illusory. Further detailed genetic counselling was given and one week later the consultand opted for pregnancy termination.

\section{FAMILY 7}

This primiparous woman had a good result after exclusion testing and her pregnancy continued to term.

\section{FAMILY 8}

This woman underwent an exclusion test in her second pregnancy after receiving detailed genetic counselling on two occasions. Her affected mother was a sporadic case who exhibited acquired cognitive impairment and chorea. The clinical diagnosis of HD was thought most likely by a neurologist, a psychiatrist, and a clinical geneticist each of whom had a special interest in the disorder. On that basis, the consultand was counselled about the exclusion test since a predictive test was not available to her. She opted for testing in her second pregnancy and a good result was obtained. Subsequently, however, multi-infarct dementia was diagnosed in an aunt of the consultand and mutation analysis in the case of her "typically" affected mother has shown no evidence of the triplet expansion mutation, thus virtually ruling out the diagnosis of HD in this family.

\section{FAMILY 9}

This 37 year old primiparous woman underwent an exclusion test in her first pregnancy after detailed counselling was given and she had a termination on learning that the fetus had a high risk of carrying the HD gene.

\section{FAMILY 10}

The last family in this series was the only one where the father was at $50 \%$ risk of developing HD. A predictive test was requested in 1986 but the family structure was not suitable for linkage analysis. The exclusion test option was explained in 1986 and 1989. In 1992 the consultand presented in the first trimester and was recounselled. She subsequently underwent CVS to exclude HD but a high risk result was obtained and the pregnancy was terminated. The following year, the consultand became pregnant again but this time, having been informed that the HD gene had recently been isolated, her husband preferred to undergo direct testing for the HD gene mutation. Unfortunately, the triplet expansion mutation was first identified in the husband and subsequently in the fetus after the couple requested a prenatal diagnostic test. The pregnancy was then terminated.

\section{Discussion}

The most important finding in this series is that three mothers chose to continue with their pregnancy although their fetus was shown to have a high risk (nearly $50 \%$ ) of carrying the HD gene. We believe that the decisions to continue these three pregnancies were taken with mothers and their respective partners being fully aware that should the mother exhibit signs of HD in the next two decades, their child will immediately be identified as a near certain HD gene carrier. The decision to forego termination in these three cases was apparently not premeditated in that it occurred only hours before the prearranged operation and, in two cases, after admission to hospital. Undoubtedly, the decision to abort a high risk pregnancy causes great anguish ${ }^{6} 7$ but, in our experience of genetic prenatal diagnosis, the decision once made is almost always irrevocable: for example, in the west of Scotland there have been over 150 prenatal diagnoses for Duchenne muscular dystrophy (DMD) and no consultand has reversed a previous decision to undergo pregnancy termination based upon their previous appraisal of an unacceptable level of risk for DMD in the fetus. Although surveys of attitudes to presymptomatic testing for $\mathrm{HD}^{8-11}$ have sometimes been difficult to reconcile with current practice, ${ }^{12}{ }^{13}$ such surveys suggest that a significant proportion of at risk subjects intend to continue with a pregnancy even if the fetus is found to have a high risk of carrying the HD gene. We conclude, therefore, that at least a proportion of at risk families would not regard our experience as a major surprise.

We have no evidence that the partners of the consultands who reversed their decision were influential in causing this change of mind. The consultands stressed that the reversed decision was of their own volition and we observed that it was certainly not influenced by further explicit counselling on its possible consequences. The common sentiment expressed by each consultand was that they "just could not go through with it", even though this had been their stated intention until the day of the prearranged termination. Clearly, in family 4, the consultand had already undergone pregnancy termination after the first high risk exclusion test, but she simply could not bring herself to terminate her second pregnancy. All three couples are aware that the health of their child will be linked to the fate of his or her mother, but since the at risk parent in each of these families is the mother, none of the at risk children should develop juvenile HD. However, our subsequent discussions with each couple who chose to continue their high risk pregnancy have shown a diversity of opinions on fundamental issues such as whether the test result should ever be divulged to their offspring. It seems, therefore, that our experience of the HD exclusion test is potentially disastrous for at least three families. However, it is difficult to argue against the observation that these three families have simply exercised their right to make an informed choice in the face of repeated, careful explanations of the test, which stressed the counsellors' view that there is inextricable linkage of a high risk result to subsequent pregnancy termination.

Our series of exclusion test results is one of 
few to be described in detail. Other reports of HD exclusion test results have come from centres in Aberdeen, ${ }^{14}$ Wales, ${ }^{2}{ }^{15}$ and British Columbia. ${ }^{1617}$ In Aberdeen 11 pregnancies in seven subjects were tested and the at risk grandparental chromosome was present in five pregnancies each of which was terminated. From British Columbia it was reported that 11 prenatal tests (five definitive and six exclusion) were performed but only six out of seven increased risk pregnancies were terminated. ${ }^{17}$ The largest body of detailed, published data on exclusion testing comes from Cardiff ${ }^{15}$ where experience of the exclusion test has been different from our own. In the Cardiff series, 24 pregnancies from 15 woman were tested, there were 14 low risk results, and 10 high risk results which were followed by 10 terminations. Also, at the time of reporting, eight women who previously had terminated a high risk pregnancy achieved a low risk result in a subsequent pregnancy. The Cardiff workers found that even very well educated clients had considerable difficulty in understanding the principles of exclusion testing, which is not surprising given the difficulties that medical colleagues experience in understanding DNA based linkage analysis. ${ }^{18}$ Naturally, the Cardiff workers placed great emphasis on detailed genetic counselling before the test being performed. Were our consultands inadequately counselled? The same geneticist counselled every consultand in this series at least once and all consultands were counselled on at least two occasions before testing. Only one couple (family 6) who were given a high risk result did not initially appreciate its significance. The details presented above from families 3,4 , and 5 do not make these three families stand apart from the others. However, a difference between our series of cases as a whole and the Cardiff series is that the majority of consultands ( $83 \%)$ in the Cardiff series were not from Wales but came as tertiary referrals from other genetic centres in England having specifically requested the exclusion test. In contrast, the couples who we report were attending the local genetic clinic for primary genetic counselling about $\mathrm{HD}$, they did not have previous knowledge of the exclusion test, and none initially requested an appointment at our clinic to discuss the exclusion test. The fact that eight out of 10 couples had DNA work up for exclusion testing completed before pregnancy being diagnosed and the remaining two couples were also counselled about exclusion testing before conception, indicates that couples in our local series were not rushed into an exclusion test programme. Almost certainly, the couples whom we saw were comparatively less selected than those in the Cardiff series, which exhibited marked skewing of the social class distribution with an excess of upper social class couples. Possibly, therefore, west of Scotland couples, through lack of a strong selective process, were less committed to their stated intention to terminate a pregnancy which has the same genetic risk as the parent.

We have also considered whether our experience may be partly related to the exclusion test's unique status in any list of prenatal diagnostic tests; it is the only situation where termination occurs when the fetus has the same genetic risk as the apparently healthy parent. Thus, a mother (in our series the mother was the parent at risk of HD in nine out of 10 families) who has a high risk exclusion result faces up to termination of her pregnancy and simultaneously confronts her own risk of developing $\mathrm{HD}$. It is also notable that there was a preponderance of high risk results (9:4) in our small series. In contrast, in a report of presymptomatic test results from the United Kingdom, there was a significant excess of low risk or good results and to account for this it was postulated that some apparently healthy, at risk relatives may have a subjective but accurate opinion that they carry the HD gene and therefore do not come forward for testing. ${ }^{12}$ Such bias should not influence the ratio of high risk to low risk exclusion test results unless additional factors are operating. For example, could the women to whom we gave high risk results have harboured private doubts about their own freedom from HD? Conceivably, such doubts may cause hesitation in finally deciding to terminate a high risk pregnancy because this action could be perceived by the at risk parent as effectively admitting the diagnosis of HD in herself. However, in the absence of data this is simply conjecture. In fact, one of the few firm observations we are able to make is that none of the couples in our series suggested that optimism about the prospect for treatment is a good reason for declining termination.

In addition to the main finding discussed above, we also encountered a more predictable problem with prenatal exclusion testing, namely, management of the sporadic case. Before the availability of DNA analysis for HD, it was our practice to counsel close relatives of a "typical" sporadic case that there was a "significant" likelihood they may inherit the HD gene. The advent of presymptomatic testing based upon the genetic linkage approach could not influence this counselling since relatives of a sporadic case could not themselves undergo prediction. However, in our opinion, prenatal (or adult) exclusion testing remained an option for such relatives since, on one hand, it was difficult to offer families a likely genetic diagnosis while, on the other hand, simultaneously withdrawing a recognised means of preventing its transmission. Hence, we were drawn into performing two exclusion tests in two families where only one person was affected and, subsequently, HD was confirmed in only one of these families. Recently, Andrew et al ${ }^{19}$ highlighted different reasons for incorrect diagnosis of HD including misdiagnosis, sample mix up, and clerical error. Although such pitfalls are now avoidable, especially with identification of the expanded CAG repeat, it is not inconceivable that the very same pitfalls may be encountered in the future by colleagues who offer prenatal exclusion and postnatal presymptomatic testing for any late onset, genetically homogeneous disorder where mutation analysis is not possible. 
We wish to thank colleagues in the Human Genetic Unit in Edinburgh, especially Lilias Barron, Jon Warner, and Susan Holloway for performing molecular genetic analyses and also Drs Martin Whittle, Margaret McNay, and their colleagues in the Prenatal Diagnosis Unit of the Queen Mother's Hospital, Yorkhill, who carried out chorion villus sampling procedures. The financial support of the Association to Combat Hunntington's Association and and the Huntington's Disease Association), the Greater Glasgow acknowledged.

1 Harper PS, Sarfarazi $M$. Genetic prediction and family structure in Huntington's chorea. BMF 1985;290:1929 31.

2 Quarrell OWJ, Meredith AL, Tyler A, et al. Exclusion testing for Huntington's disease in pregnancy with a closely linked DNA marker. Lancet 1987;i:1281-3.

3 Bloch M, Hayden MR. Preclinical testing in Huntington's disease. Am ₹ Med Genet 1987;27:733-4.

4 Brock DJH, Mennie M, Curtis A, et al. Predictive testing for Huntington's disease using linked DNA markers. Lancet 1989;ii:463-6.

5 Lathrop GM, Lalouel JM. Easy calculation of lod scores and genetic risks on small computers. Am 7 Hum Genet 1984;36:460-5.

6 Donnai D, Charles N, Harris R. Attitudes of patients after 'genetic' termination of pregnancy. $B M F$ 1981;282:621-2.

7 White-Van Mourik M, Connor JM, Ferguson-Smith MA. The psychosocial sequelae of a second trimester termination of pregnancy for fetal abnormality. Prenat Diagn 1992;12:189-204.

8 Kessler S, Field T, Worth L, Mosbarger H. Attitudes of persons at risk for Huntington disease toward predictive . Am F Med Genet 1987;26:259-70.

9 Markel DS, Young AB, Penney JB. At risk persons' attitudes toward presymptomatic and prenatal testing of Huntington disease in Michigan. Am $\mathcal{f}$ Med Genet 1987;26: 295-305.

10 Mastromauro C, Myers RH, Berkman B. Attitudes toward presymptomatic testing in Huntington disease. $\mathrm{Am} \mathcal{f}$ Med Genet 1987;26:271-82.

11 Meissen GJ, Berchek RL. Intended use of predictive testing by those at risk for Huntington disease. Am $\mathcal{F}$ Med Genet by those at risk for

12 Craufurd D, Dodge A, Kerzin-Storrar L, et al. Uptake of presymptomatic predictive testing for Huntington's disease. Lancet 1989;ii:603-5.

13 Tyler A, Ball D, Craufurd D. Presymptomatic testing for Huntington's disease in the United Kingdom. BMF 1992; 304:1593-5.

14 Simpson SA, Bessen J, Alexander D, et al. One hundred requests for predictive tests for Huntington's disease. Clin Genet 1992;41:326-30.

15 Tyler A, Quarrell O, Lazarou L, et al. Exclusion testing in pregnancy for Huntington's disease. f Med Genet 1990; 27:488-95.

16 Hayden MR, Hewitt J, Kastelein JJ, et al. First trimester prenatal diagnosis for Huntington's disease with DNA prenatal diagnosis for Huntingtor

17 Adam S, Wiggins S, Whyte $P$, et al. Five year study of prenatal testing for Huntington's disease: demand, attitudes, and testing for Huntington's disease: demand, attitudes, an

18 Mennie ME, Holloway SM, Brock DJH. Attitudes of general practitioners to presymptomatic testing for Huntington's disease. $\mathcal{F}$ Med Genet 1990;27:224-7.

19 Andrew SE, Goldberg YP, Kremer B, et al. Huntington disease without CAG expansion: phenocopies or errors in assignment? Am f Hum Genet 1994;54:852-63. 